\title{
Vitamin D receptor gene polymorphisms modulate the clinico-radiological response to vitamin D supplementation in knee osteoarthritis
}

\author{
Divya Sanghi ${ }^{1 *}$, RN Srivastava', Sarita Agarwal ${ }^{2}$ \\ From International Conference on Human Genetics and 39th Annual Meeting of the Indian Society of \\ Human Genetics (ISHG) \\ Ahmadabad, India. 23-25 January 2013
}

\section{Background}

Vitamin D receptor (VDR) gene plays an important role in bone mass regulation and is demonstrated in human articular chondrocytes of cartilage. We have previously shown a beneficial effect of vitamin $\mathrm{D}$ on symptomatic improvement in Osteoarthritis knee (KOA) patients. This study investigated whether the clinic-radiological response to vitamin D was modulated by VDR gene.

\section{Materials and methods}

This randomized placebo-controlled trial recruited 103 KOA cases as per American College of Rheumatology (ACR) guideline having vitamin D insufficiency $(25(\mathrm{OH})$ $\mathrm{D} \leq 50 \mathrm{nmol} / \mathrm{L}$ ). Enrolled cases were randomly allocated in two groups to receive placebo (51) and vitamin D (52). Primary outcome measures: pain and functional disability which were recorded by knee specific WOMAC index and secondary outcome measure were radiological features (joint space width and osteophytes). The serum levels of vitamin D were assessed by ELISA method using IDS, UK kit. Detection of VDR polymorphisms (Taq1 \& Apa I) were done by PCR-RFLP technique. 25(OH)D levels, clinical and radiological features were recorded at baseline and at one year follow up.

\section{Results}

At one year, in vitamin D group, TT genotype of TaqI polymorphism showed increment in $25(\mathrm{OH}) \mathrm{D}$ levels in comparison to $\mathrm{Tt}$ and th genotype whereas in placebo group it remained same. No such association was observed for ApaI polymorphism. In clinical features, pain significantly increased in $\mathrm{Tt}$ and $\mathrm{tt}$ genotype of placebo group whereas it decreased, although not significant in each genotype of vitamin D group. Total WOMAC scores significantly decreased in both $\mathrm{Tt}$ and $\mathrm{TT}(\mathrm{p}<0.05)$ genotypes in vitamin D group, whereas functional disability only in $\mathrm{Tt}(\mathrm{p}<0.05)$. In radiological features, decreased Medial-JSW was observed in tt genotype and increased Osteophyte was observed in TT and Tt genotype of placebo group whereas no significant changes were noted in vitamin $\mathrm{D}$ group. No such effect was observed with ApaI polymorphism.

\section{Conclusions}

VDR gene polymorphisms influence the clinico-radiological response to vitamin D supplementation in KOA Bottom of Fo with low 25-OHD levels.

\section{Authors' details}

'King George's Medical University, Near Daligunj Chauraha, Lucknow, India. ${ }^{2}$ Post Graduate Institute of Medical sciences, Raibareily Road, Lucknow, India.

Published: 21 January 2014

doi:10.1186/1755-8166-7-S1-P13

Cite this article as: Sanghi et al:: Vitamin D receptor gene

polymorphisms modulate the clinico-radiological response to vitamin D supplementation in knee osteoarthritis. Molecular Cytogenetics 2014 7(Suppl 1):P13.

\footnotetext{
${ }^{1}$ King George's Medical University, Near Daligunj Chauraha, Lucknow, India Full list of author information is available at the end of the article
} 